\title{
The Impact of Teaching Self-Regulated Learning Skills to First Year Engi- neering Students
}

\section{Dr. Rachel McCord, University of Tennessee - Knoxville}

Rachel McCord is a a Lecturer in the Engineering Fundamentals Division at the University of Tennessee in Knoxville. She received her Ph.D. in Engineering Education from Virginia Tech. Her research interests include the impact of metacognitive and self-regulated learning development on engineering student success, particularly in the first year. 


\title{
The Impact of Teaching Self-Regulated Learning Skills to First Year Engineering Students
}

\begin{abstract}
This work in progress paper focuses on the development of a pilot student success course focused on developing the self-regulated learning skills of engineering students. Many students enter the engineering disciplines vastly unprepared to be successful in the rigors of engineering academia. Student retention numbers in engineering are low and some researchers attribute this low retention rate to a lack of academic skills needed to be successful. One theoretical framework that describes these needed academic skills is self-regulated learning. Self-regulated learning (SRL) is the process that a learner goes through to enact and sustain cognitive functioning, behaviors, and metacognitive functioning to reach a set goal or goals. SRL is a complex process that includes the learner's beliefs about their own learning, motivations, preexisting knowledge, and cognitive and metacognitive skills. It is a commonly held belief in education that the most effective students in a learning environment are the students who have a high level of awareness about their own knowledge level and take control of their own learning processes; these students are referred to as self-regulated learners. Though there are many different perspectives that provide different views of SRL, in general SRL theorists "view students as metacognitively, motivationally, and behaviorally active participants in their own learning process."
\end{abstract}

A new First Year Studies (FYS) course at the university has been developed specifically for engineering students that focuses on teaching SRL skills. While FYS courses are not new to universities, data has shown that FYS courses are typically underutilized by engineering students, mainly due to their generic nature. Thus, this new course specifically targets engineering students and was designed to meet their needs. A quantitative study was conducted to determine the effectiveness of this new course at developing SRL skills by comparing an experimental and control group of students in a first year engineering course. The experimental group consists of students taking the first year engineering course AND the new FYS course. The control group consists of students only taking the first year engineering course. For the quantitative portion of the study, all participants (control and experimental) were asked to complete a pre and post survey, which consisted of the Motivated Strategies of Learning Questionnaire (MSLQ) and several demographic questions. The MSLQ was used to categorize students as low, medium, and high self-regulated learners. Participant grades in the first year engineering course were also collected to look at the performance of the control and experimental groups. The quantitative data will be used to determine if the FYS 101 course had a significant impact on the SRL skills and performance of the experimental group when compared to the control group. Data collection for this project is on-going and results will be presented in the full paper. 


\section{Introduction}

Many students enter the engineering disciplines vastly unprepared to be successful in the rigors of engineering academia. Student retention numbers in engineering are low [1] and some researchers attribute this low retention rate to a lack of academic skills needed to be academically successful [2]. This work in progress paper, framed by the theory of self-regulated learning, discusses a quantitative study conducted to look at the impact of an academic student success course developed to teach self-regulated learning skills to engineering students in the first year. This paper focuses on the initial data collection round as well as implications from the data analysis that will inform the second iteration of the academic success course.

\section{SRL Theory}

Self-regulated learning (SRL) is the process that a learner goes through to enact and sustain cognitive functioning, behaviors, and metacognitive functioning to reach a set goal or goals [3]. SRL is a complex process that includes the learner's beliefs about their own learning, motivations, pre-existing knowledge, and cognitive and metacognitive skills. It is a commonly held belief in education that the most effective students in a learning environment are the students who have a high level of awareness about their own knowledge level and take control of their own learning processes [4]; these students are referred to as self-regulated learners. Though there are many different perspectives that provide different views of SRL, in general SRL theorists "view students as metacognitively, motivationally, and behaviorally active participants in their own learning process" [5]. Thus, we can summarize most major SRL theories with the generalized framework of SRL, shown in Figure 1.

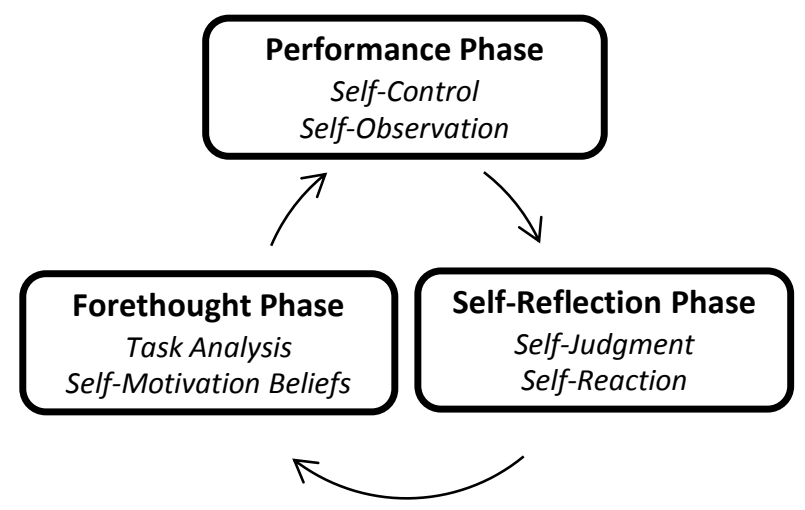

Figure 1 Phases and Sub processes of Self-Regulated Learning [6]

While self-regulated learning is an important skill set for learners, many students do not possess the skills necessary to self-regulate their learning. Most engineering school in the country suffer from a 'content overload' condition. Engineering curricular are packed with a large amount of content that must be covered before a student can graduate. Due to this issue, many believe that there is little time to teach students how to be academically success. More so, many faculty and engineering institutions seem to believe that students should enter engineering institutions with 
all the skills they need to learn and that it is not the responsibility of the college to teach students how to be academically success. Yet, our US institutions still suffer from low retention of engineering students across four years and an undergraduate population that lacks diversity. These issues were the impetus for the creation of a course to teaching engineering students how to develop their self-regulated learning skills.

\section{Development of a First Year Studies Course for Engineering Students}

In an effort to teach first year engineering students at a large, southern research university (LSRU) how to develop self-regulated learning skills, a course was developed and piloted in Fall 2015. This first year studies course, FYS 101-eng, was a 13 week, 1 hour credit course that was graded on an A, B, C, no credit scale. First Year Studies is a larger department at LSRU and organizes FYS 101 courses for students across the campus. While a majority of FYS 101 courses are comprised of students from all disciplines across the campus, there is a small subset of FYS 101 courses that are discipline specific (e.g., nursing and business). FYS 101-eng was the first discipline specific first year studies courses offered specifically for engineering students at LSRU. The primary objective of all FYS 101 courses across campus is to help students develop the skills they will need to be academically and personally successful in their university studies. While there is a common syllabus and required topics that all FYS 101 courses must follow during the semester, individual instructors are given freedom to organize and develop the content for their course as they see fit.

For FYS 101-eng, the purpose was to provide explicit instruction on how to develop SRL skills to aid future success in engineering coursework. To align with SRL framework, specific lessons were taught on the following subjects:

- Identifying Attitudes and Behaviors That Help and Hinder Success in Engineering School

- Explicitly Stating Goals and Developing Measures for Success

- Understanding The Teaching and Learning Process/How to Take Personal Responsibility for Own Learning

- What is Metacognition? Why is it Useful? How Can I Develop My Metacognitive Skills?

- How Do I Find My Passion in Engineering?

While these were not the only topics covered in FYS 101-eng, these topics directly related to teaching the three major process points of SRL (forethought, performance, and self-reflection).

The primary mode of instruction for FYS 101-eng was active learning. Most class meetings started with a short lecture introduction by the instructor (5-10 minutes) and the rest of the class meeting was spent in small group discussions where students would answer discussion questions and report themes of discussion back to the larger group. At the end of each class 
session, several reflection questions were assigned based on the topic of the day and students were required to write a one page reflection on how they could apply the day's topic personally. These reflections were collected and graded each week. Feedback was provided each week on the journal assignments. At the end of the semester, the students were asked to write a 7-8 page final reflection titled "Design Your Process For Becoming a World Class Engineering Student." The Design Your Process project is a nationally implemented project that asks students to provide a plan for how they will be successful in the rest of their academic engineering career. Students are asked to synthesize all they have learned in their academic success course, choose the skills that they believe are most relevant to their success, and make a specific plan they will follow to reach their goal of graduating with an engineering degree.

In order to recruit students to participate in FYS 101-eng, the course was advertised during summer orientation sessions for all incoming engineering students at LSRU. Applications were collected for students who were interested in taking the course. In total, 27 students submitted applications for FYS 101-eng. The initial enrollment for FYS 101-eng was 19. A total of 16 students finished the semester in FYS 101-eng. The initial class population was comprised of 13 males and 5 females. The initial class was also comprised of 12 students entering a common first year engineering course (FYEC), one student in the honors version of FYEC, and 5 students that entered LSRU as pre-calculus students and would begin FYEC in Fall 2015.

In an effort look at the effectiveness of the FYS 101-eng course on the development of SRL skills, this project sought to investigate the following research question:

How does an engineering specific student success course impact the self-regulated learning skills of first-year engineering students?

A larger mixed-methods research study is being conducted to answer the above research question. The discussion that follows will review the quantitative data that has been collected to date in an effort to answer this research question. The following sub-research questions are focus of this discussion:

1. What is the SRL profile of population?

2. How does SRL profile change over semester?

3. How are profiles similar and different for FYS and non-FYS students?

4. How does SRL profile impact performance between FYS and non-FYS students?

\section{Methods}

In an effort to answer the research question for this study, a quantitative study was conducted to answer four specific sub-research questions. This is a work-in-progress report on the quantitative data collection effort.

\section{$\underline{\text { Participants }}$}


Participants for this study were be grouped into two primary categories. The first category included students participating in a first year engineering course (FYEC). Specifically, these students participated in the first of a two semester series of FYECs. FYEC is a requirement for all entering first-year students in the College of Engineering at a large, southern research university (LSRU). The students taking FYEC were primarily true first-year engineering students (first semester in engineering and college). The Fall 2015, 597 students were enrolled in FYEC at the beginning of the semester.

The second category included students taking the optional FYS course for engineering students at LSRU. In Fall 2015, 17 students were enrolled in FYS at the beginning of the semester. These students included 11 students enrolled in FYEC, 1 student enrolled in the honors version of FYEC, and 5 students taking pre-calculus in order to enter FYEC in Spring 2016.

\section{$\underline{\text { Data Collection }}$}

Quantitative data was collected through survey methods. A survey instrument comprised of the Motivated Strategies of Learning Questionnaire (MSLQ) [7, 8] and demographic questions was deployed at two points during the semester. The MSLQ is a widely adopted survey instrument used in SRL research [9]. It is comprised of 15 constructs: 6 motivation constructs and 9 cognitive/metacognitive constructs. The MSLQ survey instrument was selected for this project due to its long history of use, specifically in higher education. Due to its extensive use, there are numerous higher education studies in other disciplines available for comparison and contrast.

The first survey deployment (Pre) occurred during week 8 of the Fall 2015 semester. The second survey deployment occurred during the final exam period, or week 16, of the Fall 2015 semester. Each survey deployment was sent to both FYEC and FYS 101-eng. Extra credit for survey participation was offered in each class. Students participating in the survey could receive extra credit without consenting to the research study. A demographic question asking about participation in FYS 101-eng was used to separate the two participant populations. All participants not enrolled in FYS 101-eng were used as a control baseline to compare against the FYS 101-eng participants. The first and second survey deployments were used to investigate differences in reported SRL skill level over time. Participant final grades were also collected for FYEC. These course grades were used to investigate the impact of SRL skill level on performance in the FYEC course.

Table 1 provides a view of the data collection and analysis procedure for each of the subresearch questions defined for this work-in-progress report. 


\begin{tabular}{|l|l|l|l|}
\hline \multicolumn{4}{|c|}{ Table 1: Data Collection and Analysis Procedure } \\
\hline & Research Question & Data Collection & Data Analysis \\
\hline 1 & $\begin{array}{l}\text { What is the SRL profile of } \\
\text { population? }\end{array}$ & MSLQ & Cluster Analysis of Pre and Post Data \\
\hline 2 & $\begin{array}{l}\text { How does SRL profile } \\
\text { change over semester? }\end{array}$ & MSLQ & $\begin{array}{l}\text { Paired Sample T-test between Pre } \\
\text { and Post Data }\end{array}$ \\
\hline 3 & $\begin{array}{l}\text { How are profiles similar } \\
\text { and different for FYS and } \\
\text { non-FYS students? }\end{array}$ & MSLQ & $\begin{array}{l}\text { Description of FYS 101-eng } \\
\text { students; Comparison of FYS and } \\
\text { non-FYS MSLQ responses }\end{array}$ \\
\hline 4 & $\begin{array}{l}\text { How does SRL profile } \\
\text { impact performance } \\
\text { between FYS and non- } \\
\text { FYS students? }\end{array}$ & $\begin{array}{l}\text { MSLQ } \\
\text { FYEC Final Grades }\end{array}$ & $\begin{array}{l}\text { Analysis of Variance between FYS } \\
\text { and Non-FYS participants }\end{array}$ \\
\hline
\end{tabular}

\section{Data Analysis and Results}

Table 2 shows the demographic information of the participants responding to the pre and post surveys. Participant counts and percentage of the total population are provided. While fewer participants participated in the post survey, the distribution among different demographic categories did not change dramatically between the pre and post surveys.

\begin{tabular}{|c|c|c|c|c|}
\hline & \multicolumn{2}{|c|}{ Pre } & \multicolumn{2}{|c|}{ Post } \\
\hline \multicolumn{5}{|c|}{ Students in FYS 101-eng } \\
\hline Yes & 5 & $2 \%$ & 3 & $2 \%$ \\
\hline No & 235 & $98 \%$ & 169 & $98 \%$ \\
\hline \multicolumn{5}{|c|}{ Reported Sex } \\
\hline Male & 154 & $64 \%$ & 111 & $65 \%$ \\
\hline Female & 82 & $34 \%$ & 59 & $34 \%$ \\
\hline Other & 1 & $0 \%$ & & $0 \%$ \\
\hline Prefer Not to Respond & 2 & $1 \%$ & 2 & $1 \%$ \\
\hline \multicolumn{5}{|c|}{ Reported Ethnicity } \\
\hline Hispanic or Latino & 5 & $2 \%$ & 5 & $3 \%$ \\
\hline Not Hispanic or Latino & 219 & $91 \%$ & 156 & $91 \%$ \\
\hline Prefer Not to Respond & 15 & $6 \%$ & 10 & $6 \%$ \\
\hline \multicolumn{5}{|c|}{ Reported Race } \\
\hline American Indian or Alaska Native & 1 & $0 \%$ & 0 & $0 \%$ \\
\hline Asian & 15 & $6 \%$ & 12 & $7 \%$ \\
\hline Black or African American & 6 & $3 \%$ & 5 & $3 \%$ \\
\hline White & 190 & $79 \%$ & 145 & $84 \%$ \\
\hline Other & 15 & $6 \%$ & 4 & $2 \%$ \\
\hline Prefer Not to Respond & 12 & $5 \%$ & 6 & $3 \%$ \\
\hline Total & 240 & & 172 & \\
\hline
\end{tabular}




\section{Sub-RQ 1: SRL Profiles}

In order to establish SRL profiles of the participants, a cluster analysis was conducted on the pre and post survey data sets separately. The cluster analysis provided three distinct clusters in each data set. The variable values for each cluster are shown in Table 3.

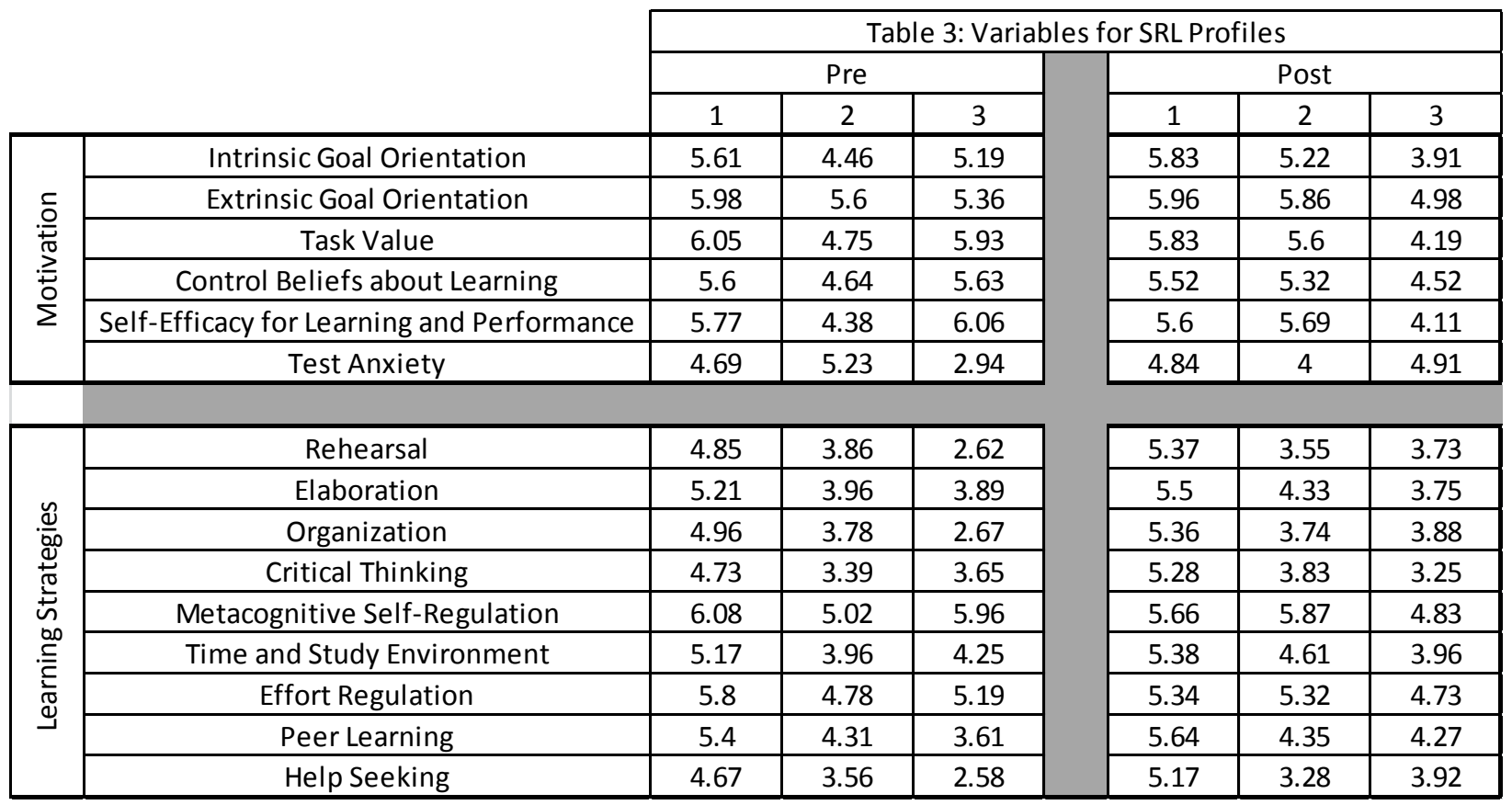

Table 4 shows a qualitative description of the variable levels for each cluster. Based on this qualitative description, we can describe each cluster in the following manner:

Cluster 1: Participants in cluster 1 report an overall high level of motivation towards the FYEC course as well as a high level of cognitive and metacognitive skill in the FYEC course. Participants in this category report only a moderate level of self-efficacy when compared to peers as well as a moderate level of test anxiety.

Cluster 2: Participants in cluster 2, overall, report low levels of motivation towards the FYEC as well as low levels of cognitive and metacognitive skill. Participants also report a high level of test anxiety.

Cluster 3: Participants in cluster report an overall high level of motivation towards the FYEC. They report a high level of self-efficacy and a low level of test anxiety. They report high levels of metacognitive functioning and low and moderate levels of cognitive functioning. Overall, their cognitive and metacognitive skill level is reported as moderate. 
Recent work by [10] found four classes of regulators among undergraduate students while the work of Nelson, Shell [11] found a five cluster profile when using different quantitative instruments for investigating first-year engineering student SRL.

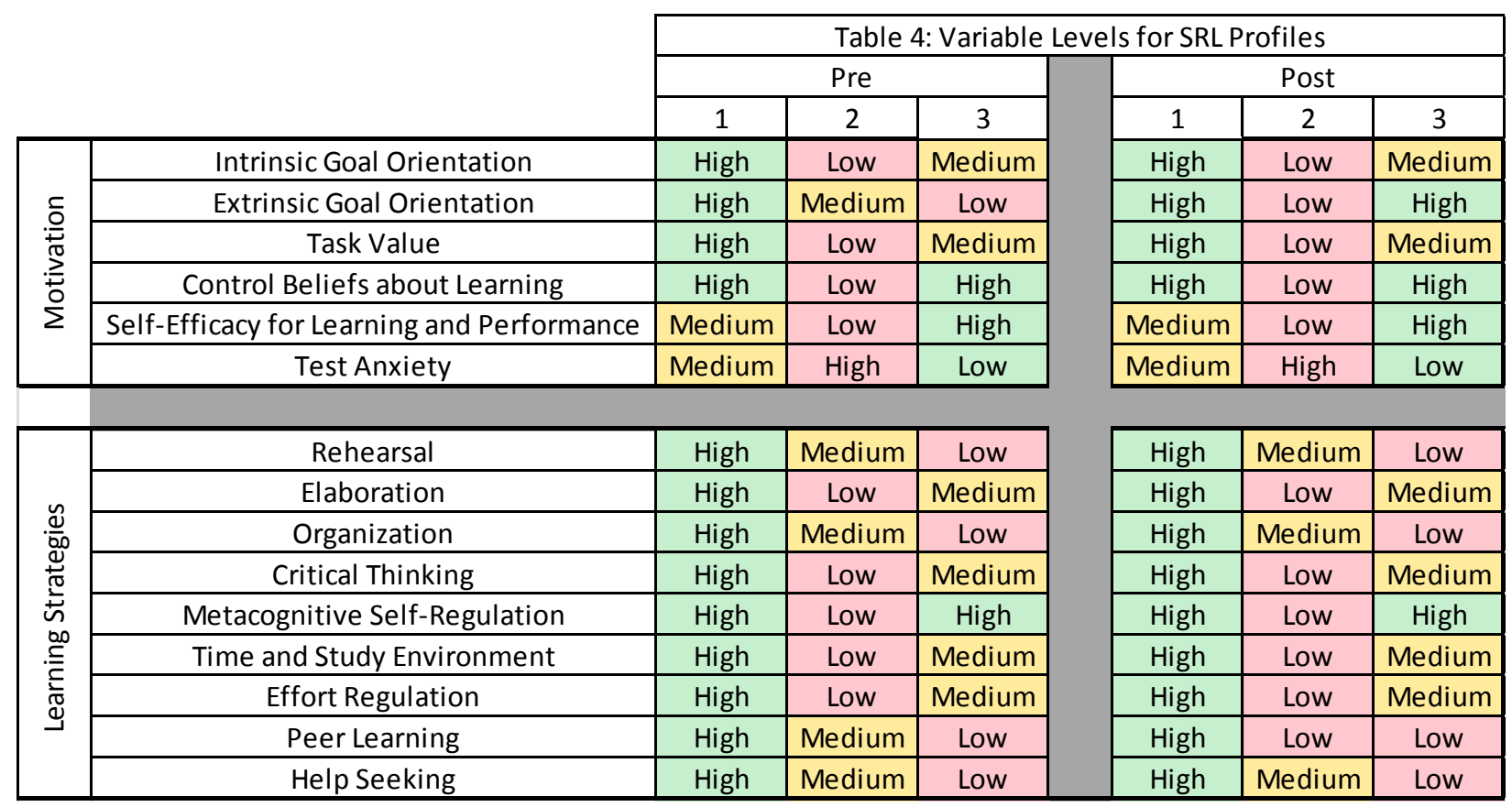

Differences in the clustering of variables between the pre and post survey deployment were minimal, which suggests that the clusters hold true across some period of time.

\section{Sub-RQ 2: SRL Difference Over Time}

To investigate the differences between reported SRL over time, paired sample t-test was used to compare the pre and post survey responses for the entire study population (FYS and non-FYS students). Table 5 reports the calculated difference for each SRL variable as well as the significance level of the difference between each variable. Variables that experienced a positive difference between the pre and post are highlighted in green. Variables that experienced a negative difference between the pre and post are highlighted in red. One notable exception to this scheme is with the variable Test Anxiety. As a high response in test anxiety is interpreted to mean that participants have high levels of test anxiety, an increase over time in test anxiety has negative consequences, and thus is noted as red. From the paired sample t-test, we see significant differences $(\mathrm{p}<0.05)$ in Task Value, Organization, Time and Study Environment and Effort Regulation. 


\begin{tabular}{|c|c|c|}
\hline \multicolumn{3}{|c|}{$\begin{array}{l}\text { Table 5: Variable Difference Between Pre-Survey and Post-Survey } \\
\text { Response }\end{array}$} \\
\hline & $\begin{array}{l}\text { Difference } \\
\text { (Post - Pre) }\end{array}$ & $\begin{array}{c}\text { Significance } \\
\text { Level } \\
\text { (2-tailed) }\end{array}$ \\
\hline Intrinsic Goal Orientation & -0.077 & 0.49 \\
\hline Extrinsic Goal Orientation & -0.168 & 0.06 \\
\hline Task Value & -0.242 & 0.04 \\
\hline Control Beliefs about Learning & -0.121 & 0.32 \\
\hline $\begin{array}{l}\text { Self-Efficacy for Learning and } \\
\text { Performance }\end{array}$ & -0.168 & 0.18 \\
\hline Test Anxiety & 0.215 & 0.09 \\
\hline Rehearsal & 0.212 & 0.10 \\
\hline Elaboration & 0.094 & 0.42 \\
\hline Organization & 0.310 & 0.01 \\
\hline Critical Thinking & 0.091 & 0.53 \\
\hline Metacognitive Self-Regulation & 0.019 & 0.86 \\
\hline Time and Study Environment & -0.320 & 0.00 \\
\hline Effort Regulation & -0.350 & 0.00 \\
\hline Peer Learning & 0.146 & 0.36 \\
\hline Help Seeking & 0.004 & 0.97 \\
\hline
\end{tabular}

\section{Sub-RQ 3: Profiles of FYS Students}

In the first round of data collection for this project, only a small number of participants came from the FYS 101-eng pool. Thus, in this work in progress paper I can only report qualitative differences between the FYS and non-FYS participants. Future work will include a larger pool of FYS participants and statistically significant data analyses can be conducted.

Table 6 shows a qualitative summary of the clusters of FYS 101-eng participants from the survey data collection. Of the FYS 101-eng students participating in the survey data collection, only clusters 2 and 3 are represented.

\begin{tabular}{|c|c|c|}
\hline \multicolumn{3}{|c|}{$\begin{array}{l}\text { Table 6: SRL Profile Information for } \\
\text { FYS } 101 \text { Students }\end{array}$} \\
\hline Student & $\begin{array}{l}\text { Pre-Survey } \\
\text { Cluster }\end{array}$ & $\begin{array}{l}\text { Post-Survey } \\
\text { Cluster }\end{array}$ \\
\hline 1 & 3 & \\
\hline 2 & 3 & 2 \\
\hline 3 & 2 & \\
\hline 4 & 3 & 3 \\
\hline 5 & & 3 \\
\hline
\end{tabular}


Table 7 displays the comparison of the difference in pre/post responses for the FYS participants and non-FYS participants. When comparing differences between the two groups, there are a few notable items to discuss. First, FYS participants saw a much larger increase in test anxiety than the non-FYS population. Second, FYS participants reported high levels of increased organization than non-FYS participants. Third, FYS participants saw an increase in effort regulation while non-FYS students saw a decrease in effort regulation. The FYS course may be helping participants increase their organizational skills and effort regulation while potentially ignoring or increasing their test anxiety. These results point to areas of future study, as well as considerations for the next iteration of FYS 101-eng.

\begin{tabular}{|c|c|c|}
\hline \multicolumn{3}{|c|}{$\begin{array}{l}\text { Table 7: Variable Difference Between Pre-Survey and Post- } \\
\text { Survey Response: Comparison of FYS and Non-FYS } \\
\text { Participants }\end{array}$} \\
\hline & $\begin{array}{l}\text { FYS } \\
\text { Class } \\
(\mathrm{n}=2)\end{array}$ & $\begin{array}{l}\text { Non- } \\
\text { FYS } \\
\text { Class } \\
(\mathrm{n}=97)\end{array}$ \\
\hline Intrinsic Goal Orientation & -0.17 & -0.08 \\
\hline Extrinsic Goal Orientation & -0.33 & -0.16 \\
\hline Task Value & -0.50 & -0.24 \\
\hline Control Beliefs about Learning & -0.50 & -0.11 \\
\hline $\begin{array}{l}\text { Self-Efficacy for Learning and } \\
\text { Performance }\end{array}$ & 0.08 & -0.17 \\
\hline Test Anxiety & 1.84 & 0.18 \\
\hline Rehearsal & -0.84 & -0.20 \\
\hline Elaboration & 0.08 & 0.09 \\
\hline Organization & 2.00 & 0.27 \\
\hline Critical Thinking & -0.75 & 0.11 \\
\hline Metacognitive Self-Regulation & -0.11 & 0.02 \\
\hline Time and Study Environment & -0.25 & -0.32 \\
\hline Effort Regulation & 0.50 & -0.37 \\
\hline Peer Learning & 0.25 & 0.14 \\
\hline Help Seeking & -1.00 & 0.02 \\
\hline
\end{tabular}

\section{Sub-RQ 4: SRL Impact on Performance}

Table 8 shows a comparison of the FYS and non-FYS participants' performance in the FYEC course. For each cluster, the average final grade in FYEC is displayed. An analysis of variance (Table 9) for the final grade between each cluster showed a significant difference between the 
non-FYS clusters but no significant difference among the FYS clusters. This lack of significance is likely due to the low number of FYS participants.

\begin{tabular}{|c|c|c|c|c|}
\hline \multicolumn{5}{|c|}{$\begin{array}{c}\text { Table 8: Final Grade Performance for SRL Profile } \\
\text { Clusters: Non-FYS and FYS Participants }\end{array}$} \\
\hline \multirow{2}{*}{} & Cluster & $\begin{array}{c}\text { Average } \\
\text { Final } \\
\text { Grade }\end{array}$ & $\mathrm{N}$ & $\begin{array}{c}\text { Std. } \\
\text { Deviation }\end{array}$ \\
\hline Non- & 1 & 85.3 & 67 & 8.02 \\
\cline { 2 - 5 } FYS & 2 & 82.1 & 52 & 8.51 \\
\cline { 2 - 5 } Students & 3 & 89.5 & 50 & 6.10 \\
\hline FYS & 2 & 92.5 & 2 & 4.12 \\
\cline { 2 - 5 } Students & 3 & 86.4 & 1 & \\
\hline
\end{tabular}

\begin{tabular}{|c|c|c|c|c|c|c|}
\hline & & $\begin{array}{l}\text { Sum of } \\
\text { Squares }\end{array}$ & $\mathrm{df}$ & $\begin{array}{c}\text { Mean } \\
\text { Square }\end{array}$ & $\mathrm{F}$ & Sig. \\
\hline \multirow{3}{*}{$\begin{array}{c}\text { Non- } \\
\text { FYS } \\
\text { Students }\end{array}$} & $\begin{array}{c}\text { Between } \\
\text { Groups }\end{array}$ & 1392.329 & 2 & 696.164 & 11.842 & .000 \\
\hline & $\begin{array}{l}\text { Within } \\
\text { Groups }\end{array}$ & 9758.436 & 166 & 58.786 & & \\
\hline & Total & 11150.765 & 168 & & & \\
\hline \multirow{3}{*}{$\begin{array}{c}\text { FYS } \\
\text { Students }\end{array}$} & $\begin{array}{c}\text { Between } \\
\text { Groups }\end{array}$ & 24.563 & 1 & 24.563 & 1.450 & .441 \\
\hline & $\begin{array}{l}\text { Within } \\
\text { Groups }\end{array}$ & 16.936 & 1 & 16.936 & & \\
\hline & Total & 41.499 & 2 & & & \\
\hline
\end{tabular}

What is striking in this performance analysis is that cluster 3 students outperformed cluster 2 AND cluster 1 students in the FYEC. The cluster 3 profile showed that participants reported high motivation but only moderate levels of cognitive and metacognitive skills while cluster 1 reported high levels in motivation, cognition and metacognition. Thus this response is surprising when looking at the clustering alone. The literature suggests a few possible reasons why this response occurred. First, self-efficacy and test anxiety may play a more distinct role in grade performance than many of the other factors investigated in this particular study [12, 13]. Cluster 3 participants reported higher levels of self-efficacy, lower levels of test anxiety when compared to cluster 1. Future work will further investigate how these factors play a role in performance. Second, many SRL theorists believe that participants may have difficulty accurately assessing their levels of SRL skills [14-16]. A call for qualitative measures as well as studies conducted in true learning contexts may provide a more accurate picture of a participants actual skill [17]. 
This is noted to say that participants in cluster 1 may be over reporting their SRL skill while cluster 2 and 3 participants may be under reporting their SRL skill. Future work will investigate the use of qualitative methods to investigate SRL in true learning contexts.

\section{Conclusions}

The initial data collection for investigating the impact of the FYS curriculum on the development has provided a number of interesting path forwards for this project. First, a continued effort in collecting data using the MSLQ in the FYEC and FYS 101-eng course will help to further confirm the three cluster profiles present in the first year engineering program. Once these profiles are confirmed, future work will focus on understanding better how these profiles impact students' performance as well as approaches to learning in their first year of engineering. Second, continued data collection will also help provide a larger data set to compare the non-FYS population with the FYS 101-eng population. Finally, this initial data set provides some insight as to potential modifications to the FYS curriculum. Specifically, I believe that a focus on dealing with test anxiety, activities to help students identify barriers to increased effort regulation, and instruction to increase task value towards engineering seems a critical component in order to provide an overall increase in self-regulated learning in this first year engineering program.

\section{References}

1. Institute of Medicine, National Academy of Sciences, and National Academy of Engineering, Rising Above the Gathering Storm: Energizing and Employing America for a Brighter Economic Future. 2007, Washington, DC: The National Academies Press. 592.

2. Hilpert, J.C., et al., Examining students' future time perspective: Pathways to knowledge building. Japanese Psychological Research, 2012. 54(3): p. 229-240.

3. Corno, L., Work Habits and Self-Regulated Learning: Helping Students to Find a "Will" from a "Way", in Motivation and self-regulated learning: Theory, research, and applications, D.H. Schunk, amp, and B.J. Zimmerman, Editors. 2012, Routledge.

4. Butler, D.L. and P.H. Winne, Feedback and Self-Regulated Learning: A Theoretical Synthesis. Review of educational research, 1995. 65(3): p. 245-281.

5. Zimmerman, B.J., Becoming a self-regulated learner: Which are the key subprocesses? Contemporary Educational Psychology, 1986. 11(4): p. 307-313.

6. Zimmerman, B.J., Investigating self-regulation and motivation: Historical background, methodological developments, and future prospects. American Educational Research Journal, 2008. 45(1): p. 166-183.

7. Pintrich, P.R., Reliability and Predictive Validity of the Motivated Strategies for Learning Questionnaire (MSLQ). Educational and psychological measurement, 1993. 53(3): p. 801.

8. Pintrich, P.R., et al., A Manual for the use of the motivated strategies for learning questionnaire (MSLQ). 1991, Ann Arbor, Mich.; [Washington, DC]: University of Michigan ; U.S. Dept. of Education, Office of Educational Research and Improvement, Educational Resources Information Center. 
9. Credé, M. and L.A. Phillips, A meta-analytic review of the Motivated Strategies for Learning Questionnaire. Learning and Individual Differences, 2011. 21(4): p. 337-346.

10. McCardle, L. and A.F. Hadwin, Using multiple, contextualized data sources to measure learners' perceptions of their self-regulated learning. Metacognition and Learning, 2015. 10(1): p. 43-75.

11. Nelson, K.G., et al., Motivational and Self-Regulated Learning Profiles of Students Taking a Foundational Engineering Course. Journal of Engineering Education, 2015. 104(1): p. 74-100.

12. Lent, R.W., S.D. Brown, and K.C. Larkin, Relation of self-efficacy expectations to academic achievement and persistence. Journal of counseling psychology, 1984. 31(3): p. 356.

13. Chapell, M.S., et al., Test Anxiety and Academic Performance in Undergraduate and Graduate Students. Journal of Educational Psychology, 2005. 97(2): p. 268.

14. Winne, P.H. and N.E. Perry, Measuring self-regulated learning, in Handbook of self-regulation, M. Boekaerts, P.R. Pintrich, and M. Zeidner, Editors. 2000, Academic Press: San Diego, CA, US. p. 531-566.

15. Karabenick, S.A. and A. Zusho, Examining approaches to research on self-regulated learning: conceptual and methodological considerations. Metacognition and Learning, 2015. 10(1): p. 151163.

16. Pintrich, P.R., C.A. Wolters, and G.P. Baxter, Assessing Metacognition and Self-Regulated Learning, in Issues in the Measurement of Metacognition, G. Schraw and J.C. Impara, Editors. 2000, Buros Institute of Mental Measurements: Lincoln, NE. p. 43-98.

17. Perry, N.E., Introduction: Using Qualitative Methods to Enrich Understandings of Self-Regulated Learning. Educational psychologist, 2002. 37(1): p. 1-3. 